Portland State University

PDXScholar

$9-1-2007$

\title{
Self-assembled biomimetic antireflection coatings
}

\author{
Nicholas C. Linn \\ University of Florida \\ Chih-Hung Sun \\ University of Florida \\ Peng Jiang \\ University of Florida \\ Bin Jiang \\ Portland State University
}

Follow this and additional works at: https://pdxscholar.library.pdx.edu/mth_fac

Part of the Mathematics Commons

Let us know how access to this document benefits you.

\section{Citation Details}

Linn, N. C., Sun, C., Jiang, P., \& Jiang, B. (2007). Self-assembled biomimetic antireflection coatings. Applied Physics Letters, 91(10), 101108

This Article is brought to you for free and open access. It has been accepted for inclusion in Mathematics and Statistics Faculty Publications and Presentations by an authorized administrator of PDXScholar. Please contact us if we can make this document more accessible: pdxscholar@pdx.edu. 


\title{
Self-assembled biomimetic antireflection coatings
}

\author{
Nicholas C. Linn, Chih-Hung Sun, and Peng Jiang ${ }^{a}$ \\ Department of Chemical Engineering, University of Florida, Gainesville, Florida 32611 \\ Bin Jiang \\ Department of Mathematics and Statistics, Portland State University, Portland, Oregon 97201
}

(Received 30 July 2007; accepted 20 August 2007; published online 6 September 2007)

\begin{abstract}
The authors report a simple self-assembly technique for fabricating antireflection coatings that mimic antireflective moth eyes. Wafer-scale, nonclose-packed colloidal crystals with remarkable large hexagonal domains are created by a spin-coating technology. The resulting polymer-embedded colloidal crystals exhibit highly ordered surface modulation and can be used directly as templates to cast poly(dimethylsiloxane) (PDMS) molds. Moth-eye antireflection coatings with adjustable reflectivity can then be molded against the PDMS master. The specular reflection of replicated nipple arrays matches the theoretical prediction using a thin-film multilayer model. These biomimetic films may find important technological application in optical coatings and solar cells. (c) 2007 American Institute of Physics. [DOI: 10.1063/1.2783475]
\end{abstract}

Periodic optical microstructures are abundant in biological systems and have provided enormous inspiration for scientists to mimic natural structures for practical applications. ${ }^{1-5}$ To name just a few, Morpho butterflies use multiple layers of cuticle and air as natural photonic crystals to produce striking blue color, ${ }^{2}$ inspiring the development of chemical sensors for detecting trace amount of vapors. ${ }^{4}$ Some nocturnal insects (e.g., moths) use arrays of nonclosepacked nipples with sub-300-nm size as antireflection coatings (ARCs) to reduce reflectivity from their compound eyes. ${ }^{6}$ Artificial ARCs are widely used in monitors, car dashboards, optical components, and solar cells. ${ }^{7-10}$ Existing antireflection technologies, such as quarter-wavelength multilayer films and nanoporous coatings (e.g., phaseseparated polymers and nanoparticle and polyelectrolyte multilayers) often perform suboptimally or are expensive to implement. $^{7-12}$

Inspired by the natural photonic structures, moth-eye ARCs with subwavelength protrusion arrays have been widely explored. ${ }^{6,12,13}$ However, current lithography-based fabrication techniques (e.g., photolithography or interference lithography) in creating sub-300 nm features are costly and are limited by either low resolution or small sample size. Self-assembly in synthetic materials provides an inexpensive, simple to implement, inherently parallel, and high throughput alternative to lithography in creating periodic microstructures. ${ }^{14}$ Unfortunately, most of the traditional selfassembly techniques are not compatible with standard microfabrication, impeding scale-up to an industrial-scale fabrication. ${ }^{11,15-21}$ Additionally, conventional self-assembly is limited to the creation of close-packed structures, whereas natural moth-eye ARCs exhibit nonclose-packing characteristics. ${ }^{6}$

Recently, we have developed a versatile spin-coating technology that combines the simplicity and cost benefits of bottom-up self-assembly with the scalability and compatibility of standard top-down microfabrication in creating a large variety of nanostructured materials. ${ }^{22-27}$ The technology is based on shear-aligning concentrated colloidal suspensions

\footnotetext{
${ }^{a)}$ Electronic mail: pjiang@che.ufl.edu
}

using standard spin-coating equipment, enabling the production of wafer-scale, nonclose-packed colloidal crystals. We have also demonstrated that spin-coated colloidal arrays can be used as structural templates to replicate a large variety of functional nanostructures including metallic nanohole arrays, ${ }^{26}$ magnetic nanodots, ${ }^{24}$ macroporous polymers, ${ }^{25}$ microvial arrays, ${ }^{23}$ and more. For instance, the modulated surface features of spin-coated colloidal crystals have been demonstrated as two-dimensional templates to create waferscale metallic gratings with crystalline arrays of nanovoids. ${ }^{22}$

Here we extend our previous work on spin-coatingenabled templating nanofabrication to develop a scalable nonlithographic approach to mass-fabricate large-area, motheye ARCs with nonclose-packed microstructures and adjustable reflectivity. A schematic outline of the templating procedures is shown in Fig. 1. The fabrication of wafer-scale, nonclose-packed colloidal crystals embedded in poly(ethoxylated trimethylolpropane triacrylate) (PETPTA) matrix is performed according to Ref. 25. The resulting crystals can be easily and reproducibly created over arbitrarily large areas in minutes. The long-range periodic surface protrusions of the shear-aligned crystals [similar to Fig. 2(a)] can be easily transferred to a poly(dimethylsiloxane) (PDMS) (Sylgard 184, Dow Corning) mold. The solidified PDMS mold can then be peeled off and put on top of ETPTA monomer sup-

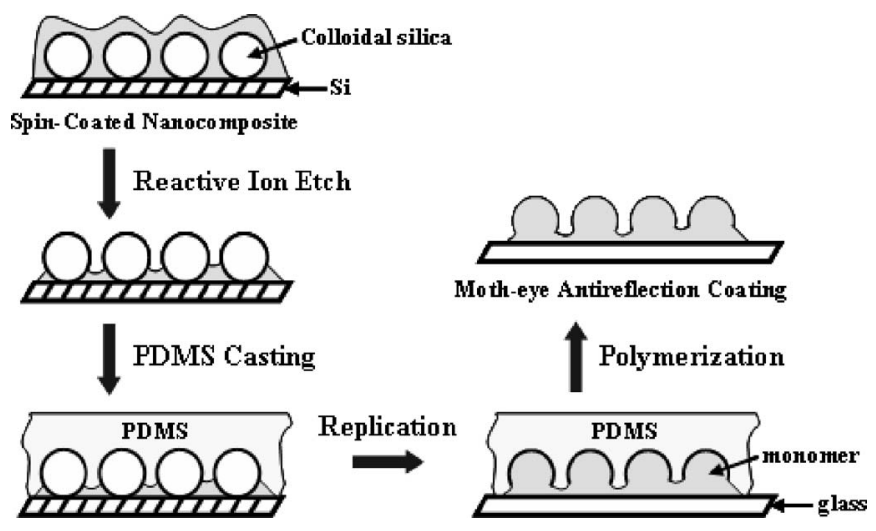

FIG. 1. Schematic illustration of the templating procedures for making moth-eye antireflection coatings. 


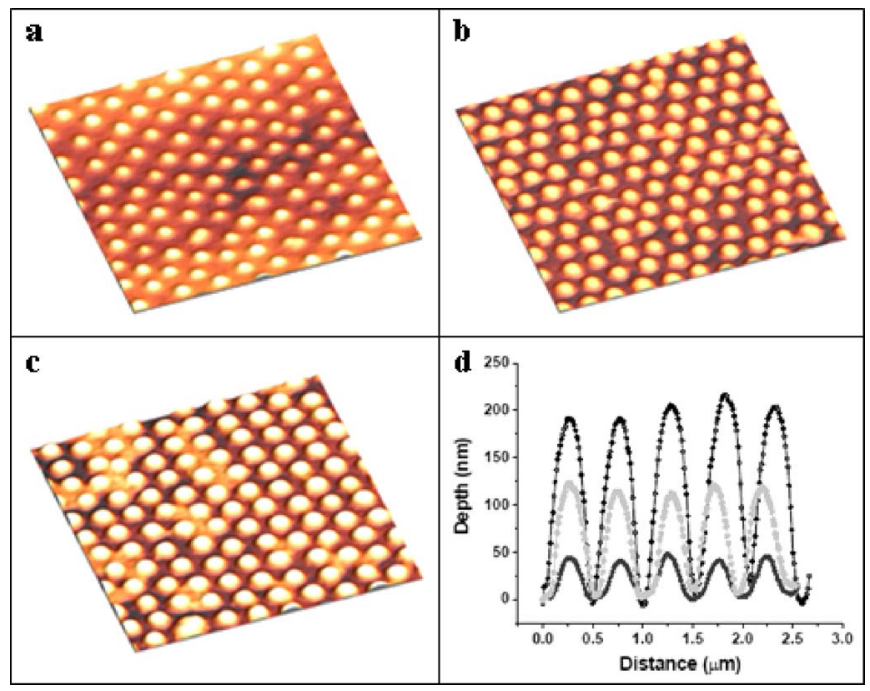

FIG. 2. (Color online) AFM images and corresponding depth profiles of replicated nipple arrays at different RIE etching times. (a) 0 s. (b) 20 s. (c) 45 s. $360 \mathrm{~nm}$ diameter silica spheres are used as templates.

ported by a glass slide with spacers (double-stick tape, thickness of $\sim 0.1 \mathrm{~mm}$ ) in between. ETPTA monomer is polymerized for $2 \mathrm{~s}$ using a Xenon pulsed UV curing system. After peeling off PDMS mold, ETPTA nipple arrays coated glass slide can be made. The flexible PDMS mold enables the creation of microstructured coatings on both planar and curved substrates.

The protrusion depth $(\sim 50 \mathrm{~nm})$ of a replicated PETPTA array from the spin-coated nanocomposite film is shallow compared to the radius of templating silica spheres $(\sim 180 \mathrm{~nm})$, as revealed by the atomic force microscope (AFM) image [Fig. 2(a)], and its corresponding depth profile (bottom curve) is shown in Fig. 2(d). The polymer matrix of spin-coated nanocomposites can be plasma-etched (using an Unaxis Shuttlelock reactive ion etcher (RIE)/inductively coupled plasma ICP operating at 40 mTorr oxygen pressure, 40 SCCM (SCCM denotes cubic centimeter per minute at $\mathrm{STP}$ ) flow rate, and $100 \mathrm{~W}$ ) to adjust the height of the protruded portions of silica spheres, resulting in good control over the depth of replicated nipples. Figures 2(b) and 2(c) show PETPTA nipple arrays replicated from the same nanocomposite sample, as shown in Fig. 2(a), after 20 and $45 \mathrm{~s}$ RIE etching, respectively. The shape of nipples in the latter sample is close to hemispherical, as revealed by the depth profile (top curve) in Fig. 2(d).

The specular optical reflectivity of the replicated nipple arrays are evaluated using visible-near-IR reflectivity measurement at normal incidence. An Ocean Optics HR4000 high resolution fiber optic UV-visible-near-IR spectrometer with a reflection probe is used for reflectance measurements. ${ }^{27}$ The resulting reflectivity is calibrated using a STAN-SSL low-reflectivity specular reflectance standard (Ocean Optics). Figures 3 and 4 illustrate the excellent control over the antireflection performance of the replicated nipple arrays by simply adjusting the RIE etching time (i.e., height of nipples). The hemispherical-like nipple arrays (dark gray curve in Fig. 3) show significantly smaller reflectivity than that of a flat control sample (black curve) for the whole visible spectrum.

A thin-film multilayer model ${ }^{6,28}$ has also been developed to calculate the specular reflectance of the replicated nipple

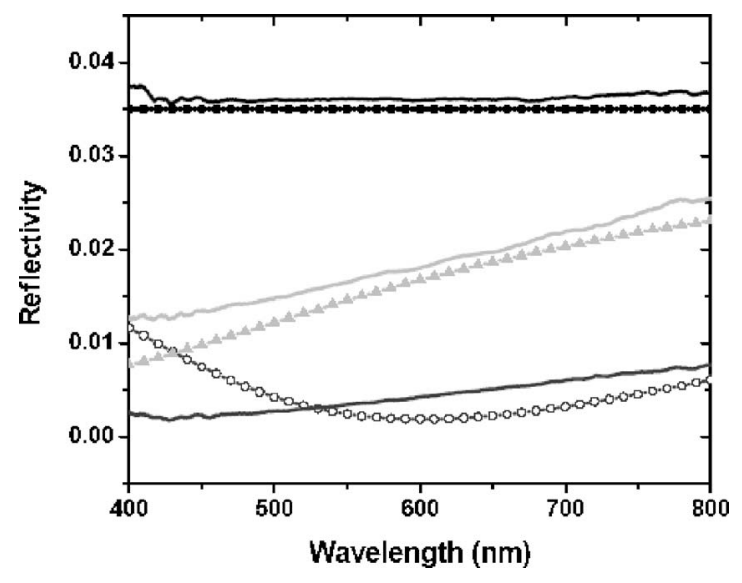

FIG. 3. Experimental (solid) and calculated (dotted) specular optical reflectivity at normal incidence. Black: flat PETPTA. Light gray: $20 \mathrm{~s}$ RIE etch, $110 \mathrm{~nm}$ spherical cap. Dark gray: $45 \mathrm{~s}$ RIE etch, $180 \mathrm{~nm}$ hemispherical cap.

arrays and then compared with experimental spectra. The nipple lattice is assumed to be hexagonal and the distance between the centers of the neighboring nipples is $\sqrt{2} d$. $^{25}$ Since the distance of the nipples is small with respect to the wavelength of light, light propagation is governed by the effective refractive index of the nipple array, which can be calculated from effective medium theory. ${ }^{28}$ We first divide the whole hemisphere cap layer in 100 layers and calculate the effective refractive index for each layer. The reflectance of each layer can then be calculated using a matrix multiplication procedure for a stack of thin layers as shown in Chap. 2 of Ref. 28. Figure 3 shows that the simulated spectra (dotted lines) match the experimental spectra (solid line) and the reflection from the PETPTA/glass interface due to index mismatch might contribute to the small discrepancy between them.

The good and adjustable antireflection performance of the replicated nipple arrays can be explained by mapping the effective refractive index across the height of nipples (Fig. 5). For featureless polymer film, the refractive index is sharply changed from 1.0 to 1.46 across the air-polymer interface, leading to high reflectance. For nipples with $50 \mathrm{~nm}$ height (cross) that are replicated directly from spin-coated nanocomposites without RIE etching, the effective refractive index is continuously changed from 1.0 (nipple peaks) to 1.09 (nipple troughs), then sharply increased to 1.46 , result-

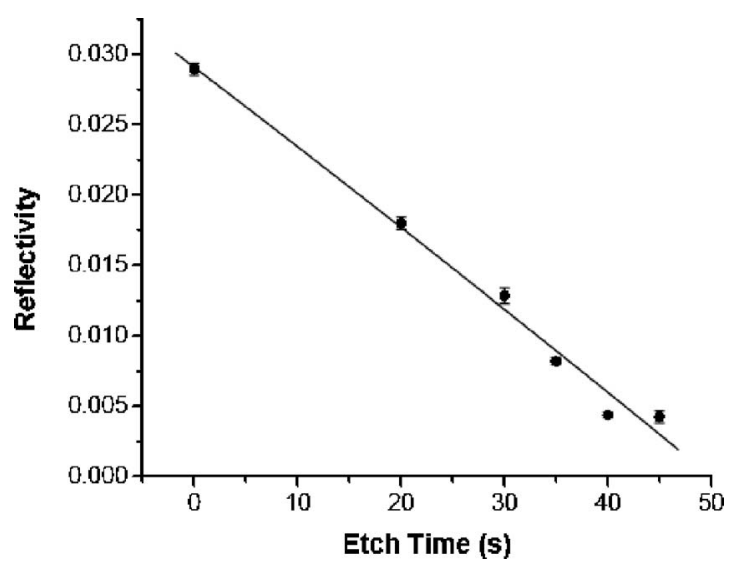

FIG. 4. Dependence of the normal-incidence optical reflectivity at $600 \mathrm{~nm}$ vs RIE etching time performed on spin-coated colloidal crystal-polymer nanocomposites. 


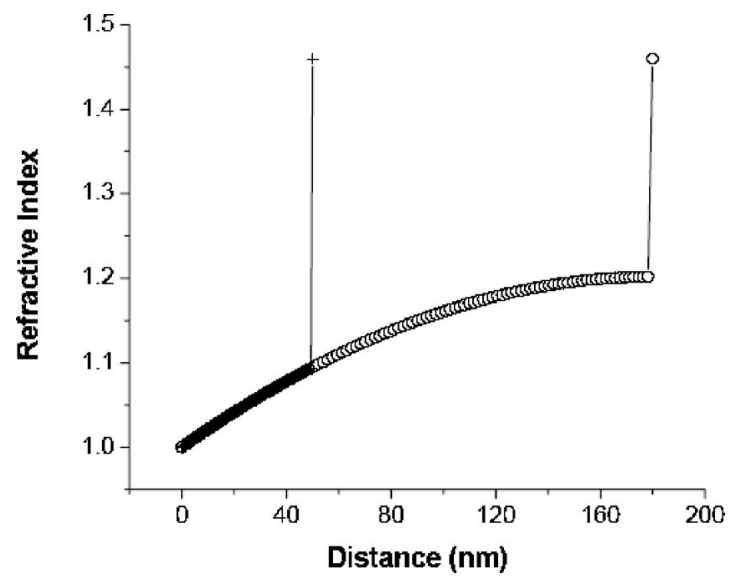

FIG. 5. Comparison of the change of calculated effective refractive index from the nipple peaks $\left(n_{\mathrm{eff}}=n_{\mathrm{air}}=1\right)$ to the nipple troughs $\left(n_{\mathrm{eff}}=n_{\text {PETPTA }}\right.$ $=1.46$ ) between hemispherical (unfilled circle) and 50-nm-height spherical cap (cross) nipple arrays. The diameter of colloidal particles is $360 \mathrm{~nm}$.

ing in reduced reflectivity (Fig. 4); while for hemispherical nipples (unfilled circle), the final step is moderate-from 1.20 to 1.46 , thus leading to minimal reflectivity.

Natural moth-eye nipples are nonclose packed, ${ }^{6}$ while bottom-up self-assembly typically produces close-packed arrays. To evaluate which structure is better for antireflective application, we compare the antireflection performance between nonclose-packed and close-packed hemispherical nipple arrays with the same height $(180 \mathrm{~nm})$ by simulation (Fig. 6). The nonclose-packed arrays show lower reflectivity when the wavelength of light is larger than the distance between the neighboring nipples $(\sqrt{2} d, \sim 500 \mathrm{~nm})$. Further simulation shows that this is a general rule for all particle

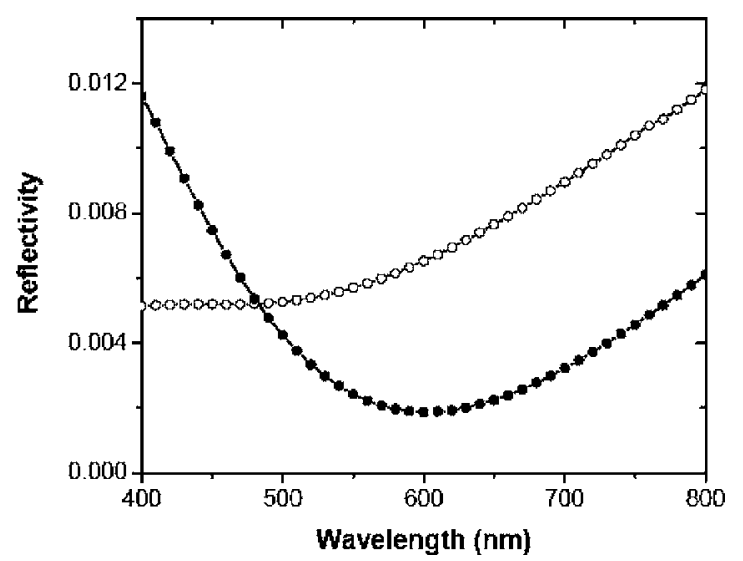

FIG. 6. Comparison of the calculated specular optical reflectivity at normal incidence between nonclose-packed (filled circle) and close-packed (unfilled circle) hemispherical nipple arrays. The diameter of colloidal particles is $360 \mathrm{~nm}$. sizes and we will conduct systematic experimental and theoretical investigations on this issue in our future work.

In summary, we have developed a simple yet scalable self-assembly approach for fabricating efficient moth-eye antireflection coatings with adjustable reflectivity and nonclose-packed microstructures, which are not easily available by traditional self-assembly approaches. The specular reflection of nipple arrays matches the theoretical prediction using a thin-film multilayer model. These biomimetic coatings may find important technological application in optical devices and solar cells.

This work was supported in part by the NSF under Grant No. CBET-0651780, the start-up funds from the University of Florida, and the UF Research Opportunity Incentive Seed Fund.

${ }^{1}$ K. H. Jeong, J. Kim, and L. P. Lee, Science 312, 557 (2006).

${ }^{2}$ P. Vukusic and J. R. Sambles, Nature (London) 424, 852 (2003).

${ }^{3}$ J. Aizenberg, D. A. Muller, J. L. Grazul, and D. R. Hamann, Science 299, 1205 (2003).

${ }^{4}$ R. A. Potyrailo, H. Ghiradella, A. Vertiatchikh, K. Dovidenko, J. R. Cournoyer, and E. Olson, Nat. Photonics 1, 123 (2007).

${ }^{5}$ T. L. Sun, L. Feng, X. F. Gao, and L. Jiang, Acc. Chem. Res. 38, 644 (2005).

${ }^{6}$ D. G. Stavenga, S. Foletti, G. Palasantzas, and K. Arikawa, Proc. R. Soc. London, Ser. B 273, 661 (2006).

${ }^{7}$ J. Hiller, J. D. Mendelsohn, and M. F. Rubner, Nat. Mater. 1, 59 (2002).

${ }^{8}$ M. Ibn-Elhaj and M. Schadt, Nature (London) 410, 796 (2001).

${ }^{9}$ S. Walheim, E. Schaffer, J. Mlynek, and U. Steiner, Science 283, 520 (1999).

${ }^{10}$ J. Q. Xi, M. F. Schubert, J. K. Kim, E. F. Schubert, M. F. Chen, S. Y. Lin, W. Liu, and J. A. Smart, Nat. Photonics 1, 176 (2007).

${ }^{11}$ B. G. Prevo, E. W. Hon, and O. D. Velev, J. Mater. Chem. 17, 791 (2007).

${ }^{12}$ S. Chattopadhyay, L. C. Chen, and K. H. Chen, Crit. Rev. Solid State Mater. Sci. 31, 15 (2006).

${ }^{13}$ P. B. Clapham and M. C. Hutley, Nature (London) 244, 281 (1973).

${ }^{14}$ G. A. Ozin and A. C. Arsenault, Nanochemistry: A Chemical Approach to Nanomaterials (RSC, Cambridge, 2005).

${ }^{15}$ J. Y. Shiu, C. W. Kuo, P. L. Chen, and C. Y. Mou, Chem. Mater. 16, 561 (2004).

${ }^{16}$ Z. Z. Wu, J. Walish, A. Nolte, L. Zhai, R. E. Cohen, and M. F. Rubner, Adv. Mater. (Weinheim, Ger.) 18, 2699 (2006).

${ }^{17}$ F. C. Cebeci, Z. Z. Wu, L. Zhai, R. E. Cohen, and M. F. Rubner, Langmuir 22, 2856 (2006).

${ }^{18}$ S. M. Yang, S. G. Jang, D. G. Choi, S. Kim, and H. K. Yu, Small 2, 458 (2006).

${ }^{19}$ P. T. Hammond, Adv. Mater. (Weinheim, Ger.) 16, 1271 (2004).

${ }^{20}$ H. Y. Koo, D. K. Yi, S. J. Yoo, and D. Y. Kim, Adv. Mater. (Weinheim, Ger.) 16, 274 (2004).

${ }^{21}$ B. G. Prevo, Y. Hwang, and O. D. Velev, Chem. Mater. 17, 3642 (2005).

${ }^{22}$ P. Jiang, Angew. Chem., Int. Ed. 43, 5625 (2004).

${ }^{23}$ P. Jiang, Chem. Commun. (Cambridge) 2005, 1699.

${ }^{24}$ P. Jiang, Langmuir 22, 3955 (2006).

${ }^{25}$ P. Jiang and M. J. McFarland, J. Am. Chem. Soc. 126, 13778 (2004).

${ }^{26}$ P. Jiang and M. J. McFarland, J. Am. Chem. Soc. 127, 3710 (2005).

${ }^{27}$ P. Jiang, T. Prasad, M. J. McFarland, and V. L. Colvin, Appl. Phys. Lett. 89, 011908 (2006).

${ }^{28}$ H. A. Macleod, Thin-Film Optical Filters, 3rd ed. (Institute of Physics, Bristol, 2001), p. 40. 
Applied Physics Letters is copyrighted by the American Institute of Physics (AIP). Redistribution of journal material is subject to the AIP online journal license and/or AIP copyright. For more information, see http://ojps.aip.org/aplo/aplcr.jsp 